\title{
Research on Industrial Design Method Based on Shape Symbolic Language of Stacked Stone in Yangzhou Geyuan Garden
}

\author{
Wenming Liu ${ }^{1, \mathrm{a}}$, Penghui Chen ${ }^{2, \mathrm{~b}}$ \\ ${ }^{1}$ School of Design and Art, Shenyang Jianzhu University, Shenyang, Liaoning, 110168,China \\ ${ }^{2}$ School of Design and Art, Shenyang Jianzhu University, Shenyang, Liaoning, 110168, China
}

\begin{abstract}
Stone stacking represents a high concentration and replication of natural mountain landscape, while stone stacking art serves as a significant element and a key tool in traditional Chinese landscape design. This paper presents the artistic background and characteristics of stone stacking. Through the analysis of the form symbol and design method of "spring, summer, autumn and winter", this paper proves that the application of cultural symbols in product design is effective and can be used as a method of auxiliary design.
\end{abstract}

\section{Background of Stone Stacking Art}

The stone stacking art originated in the Qin and Han dynasties. For the sake of his immortality, the First Emperor of Qin (Qin Shi Huang) established three sacred mountains in Xianyang, marking the commencement of the stone stacking art of classical gardens in China[1]. In the Northern Wei Dynasty, people started to consciously work with stones in gardens to build rockeries. Subsequently, "rockery" was already in use to describe the stone stacking in gardens during the Tang Dynasty, representing a turning point in the stone stacking art, acting as a transition to the next phase. In the Song Dynasty, special stone stacking craftsmen were available to build rockeries with stones. Flourishing in the Ming and Qing dynasties, the stone stacking landscaping art was gradually approaching the climax following the Ming and Qing dynasties, during which a great number of architects and theoretical works on gardening were accomplished, such as Yuan Ye by Ji Cheng and Su Yuan Shi Pu by Lin Youlin. Up to the reform and opening up, the stone stacking art has received increasing attention from designers worldwide.

In the landscape design, the formation basis of the stone stacking is subject to the influence by the idea of "unity of heaven and man"[2]. China features a vast territory, scenic water and magnificent mountains, and a profound traditional culture. Throughout the ages, people have always revered the philosophical ideology of "unity of heaven and man", and so has it been in the design of gardens. Stone stacking is one of the techniques in landscape design. In Yuan Ye by Ji Cheng (Ming Dynasty), he stated that "although made by man, it is like a heavenly creation", which is a representation of the supreme level of stone stacking in Chinese landscape design. The idea of "following the laws of development" is similar to the idea of "unity of heaven and man". In Chinese landscape design, this idea has also profoundly influenced the art of hill stacking and stone arrangement.

\section{Artistic Characteristics of Stone Stacking}

Create natural beauty. Confucius in The Analects of Confucius proposed that " the knowledgeable enjoys the water, the benevolent enjoys the mountains", reflecting the relationship between man and nature to a certain extent, and illustrating man being a member of nature[3]. In landscape design, stone stacking is utilized to embody the beauty of nature, while artificial techniques are incorporated into the design of gardens utilizing stone stacking landscape techniques. Designers should preserve the original natural properties of stone stacking as much as possible based on traditional cultural ideology while designing gardens with stone stacking techniques. In modern landscape design, the techniques of stone stacking are employed to bring people closer to nature and foster natural beauty in the landscape space.

Create the aesthetic conception. Zhang Zao, a painter in the Tang Dynasty, put forward the artistic creation theory of "artistic creation originates from the study of nature, the beauty of art stems from the inner perception", which is a representative statement of the theory of "learning the nature from the outside world" in the Chinese aesthetic history[4]. The term "good fortune" refers to the nature, while "psychological source" denotes the inner perception. The "significance" is the expression of will and emotion; the "context" refers to a certain spatial environment in which people are located. It is only the combination of "significance" and "context" that can achieve a special atmosphere. In landscape design, the stone stacking pays particular attention to the natural beauty of space in the gardening technique. In modern Chinese landscape design, stone scenery is frequently employed as an embellishment in large-scale planting 
scenery to create a natural landscape with the feeling of "a hillside can be staggered, while a stone can also evoke emotion". In turn, it can create and manifest the beauty of artistic conception, thereby achieving the realm of "finite shapes, but infinite conceptions".

Create spatial beauty. "A common feature of modern garden and stone stacking landscape is the pursuit of harmony with the environment, with emphasis on the presentation of natural wilderness and the aesthetic effect of simplicity". The ultimate objective of the application of stone stacking in landscape design lies in the creation of spatial beauty. With the use of stone stacking on the space for reasonable division, penetration and serial connection, etc., deep and layered sense of garden landscape space can be enhanced. An effort is made to achieve the landscape spatial effect of varying scenery at each step, sparseness and denseness, winding paths, and enlightened openness. For example, with regard to the composition of stone stacking landscape, "Xishu garden attaches significance to highlight the memorial space ambience and humanistic atmosphere by stone stacking", thereby fostering the spatial beauty of ancient, rustic, exquisite and elegant, being rich in local sentiment and dense in literary style.

\section{Morphological Symbolic Analysis of the Stone Stacking Art in Geyuan Garden}

Geyuan Garden is a small garden composed of symbols. Strolling through the garden, it is impossible to recognize the mystery of the four seasons concealed in this landscape by eyesight alone. The correspondence between the four scenery and the four seasons actually hinges more on the function of morphological language symbols, such as spring dream and maple leaves, rather than being truly resembled. Just like the relationship between the Chinese character "ge" and "bamboo", the four-season rockeries and "spring, summer, autumn and winter" are also a "metaphorical" relationship. Geyuan Garden is in essence a garden of "metaphor".

In the design field, morphology and modelling theory are interlinked concepts. It is obvious that this embodies the tendency of external visualization such as "modelling", "shape" and "figure" in the concept of design morphology. Nevertheless, given that design morphology involves the study of the visibility and non-visibility dimensions of man-made morphology, it is clearly not enough to interpret design morphology merely as the study of external forms. More so, the development of modern design has undergone new transformations in both connotation and extension. There has been an expansion tendency in both the areas that influence design and those in which design functions. The perception and study of design can no longer be confined to the level of appearance, but rather must be analyzed, understood and studied at the level of systems and relationships. Design morphology or modelling theory should be a more complex methodology than how they are commonly understood.

The word "morphology" encompasses not only the external state of matters, but also the state of existence, the composition form and other rich connotations. Beyond the field of design, most of the universe that exists in some form, shape and state can be represented by morphology. Regardless of the senses felt or the abstract substances and things conceived through the mind, all of them can be expressed by morphology, which is both the form of visualized substances and the state of abstract things.

For the sake of better manifesting the softness and grace of clouds by designers, top quality Taihu Lake stones with thin, transparent, leaky and wrinkled shapes were carefully selected for stacking at summer scenery. Being thin, transparent, leaky and wrinkled are the traditional criteria for stone appreciation in China. The thinness refers to the charming and graceful lines; the transparency and leakage describe the porosity and delicacy of the stone, and the wrinkles depict its vicissitudes of texture. The summer scenery primarily adopts the technique of stone stacking, which is mainly dominated by piling up hills. The exquisite transparency of the lake stone and the superior stone stacking skills convey the graceful and gentle beauty of the landscape in the south of the Yangtze River, a perfect integration of stone stacking morphology and art. The "morphology" shows no specific content of things, but features independent aesthetic characteristics. The reason for the aesthetic value of "morphology" is attributed to its natural laws and rich content accumulation, as well as its abstract and pure form, which can be "meaningful form".

\subsection{Connections and Distinctions among the Four Scenery of "Spring, Summer, Autumn and Winter"}

The so-called four-season rockery refers to the method of dividing and stacking stones, which makes use of different combinations of wood and stones to create four-season scenery for spring, summer, autumn and winter. Bamboo and bamboo-shoot-like stones creates a spring scenery (Figure 1), which represents "spring mountains and bamboo-shoot-like stones are interlaced, with the shadow of bamboos", implying the appearance of spring bamboo shoots after the rain; with the lake stone stacked with mountains, caves are in the mountains, with hollow inside and odd outside, matched with clear blue ponds, meaning summer clouds and strange peaks, which is the summer scenery (Figure 2); the piled-up hills are with maple leaves, and pavilions are built at the top of the hills, overlooking the pavilions and the yellow stones, doubling the autumnal feeling, which is the autumn scenery (Figure 3); the most imaginative landscape is probably the winter scenery (Figure 4). The rockery made of snow stones shines brightly in the light, whereas it is faintly white against the light, reminding one of the residual snow. Twenty-four wind holes are carved on the back wall to respond to the meaning of "the north wind whistling cold snow light". There are garden windows on the west wall of the winter hill, through which flowers and bamboo paths can be seen, as if there is a path to lead to spring. 


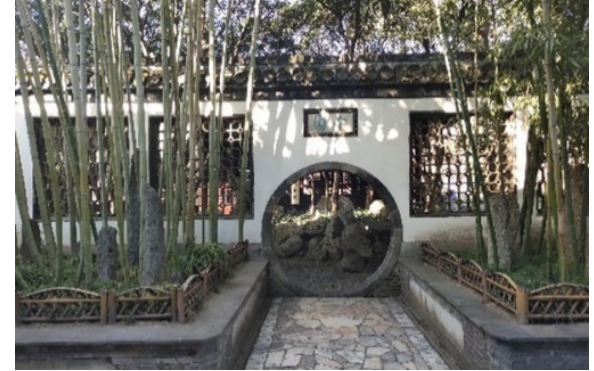

Figure 1. Spring Scenery

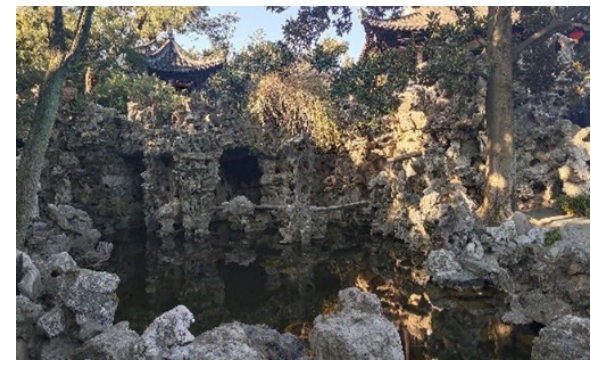

Figure 2. Summer Scenery

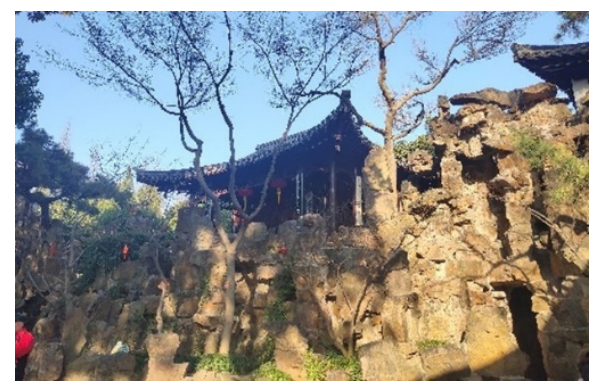

Figure 3. Autumn Scenery

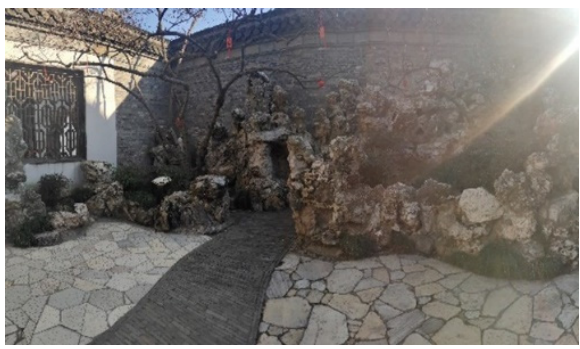

Figure 4. Winter Scenery

The metaphor about four seasons with four scenery actually encloses the four seasons of "historical time" into the small garden of "common time". The succession of four seasons signifies the passage of time. However, if one owns the four seasons in "common time", it would mean that one controls the change of four seasons, which in turn would also possess the time to stroll leisurely through at will. Spring, summer, autumn and winter are just a form of "metaphor" among the four scenery in the garden. They are close at hand, connected to each other, and circulate repeatedly, as if the four-season rockeries have been a time machine that can retain the fleeting years. In its in-depth significance, Geyuan Garden is also a garden of time[5].

\section{The design method that "spring, summer, autumn and winter" reflects by four scenes}

\subsection{Arrangement and Layout}

Despite the different stones used for the four-season rockeries, the whole garden is undulating and well organized, all in one go. The "spring scenery" is located at the entrance with the pink wall as the paper and the bamboo and stone as the painting, just like a picture of bamboo and stone, which is the "beginning"; the twelve zodiac animal signs and lake stone figurines can be considered as the continuation of the spring scenery. By passing the "spring mountain" and going around the flower hall, it naturally connects to the "summer scenery". The summer scenery is composed of lake stones, which are exquisite and transparent, embodying the conception of "stacking stones and resting clouds", which is "bearing"; the spatial transformation and change from "summer scenery" to "autumn scenery" is realized by the "Hu Tian $\mathrm{Zi}$ Chun" Mountain-Surrounding Building, which is "turning". The "autumn scenery" selects yellow stones to highlight the majestic and mighty momentum, which is the climax of the whole garden. The "winter scenery" uses Xuan stones to pile up the "snow lion picture" and ice cracks on the ground to bring out the meaning of the residual snow, which is "harmonizing". It is an extraordinary beauty that is achieved in one-shot, step-bystep manner. This concept of "beginning, bearing, turning and harmonizing" can be applied to the interaction interface of the operating system in product design, facilitating the establishment of a perfect operating system. Attention is paid to the size, shape, layout and changes of each operation code, so that users can experience the dynamic continuity at the visual level between each module, thus producing a sense of rhythm. By leading users to gradually recognize the use of the product following a certain rhythm, the operating system designed in this way can reduce the tedium brought about by the operation, increase the interestingness of the operation, draw the distance closer between users and the product, and can deliver a favorable user experience. This exemplifies the rhythm and tempo of the laws of morphological beauty in design.

\subsection{Integration of Virtual and Practical}

Autumn mountain features a charming appearance and stretches endlessly, with three peaks in the west, central and south, with the central peak being the principal one and the western and southern peaks being the supplementary ones. There is a correspondence among the three, contrasting and concealing, forming an undulating and rolling mountain terrain, and great attention is devoted to the changes in the mountain profile and the size of the caves and ravines. The central peak is the most precipitous, abrupt and stunning, as if the top of the stacked stone remains unfinished, but even more intriguing. This is the effect of the stone stackers' extensive use of the "stretching and floating" technique. "Stretching" is a stone extending 
horizontally from the mountain in the air, and "floating" is a technique of stacking vertical stones at the top of the extended blocks. If searching the way down from the mountain summit, the greatest feeling may be: the whole mountain body is "empty" inside. For the mountain per se, as it contains the meaning of hole, the concave part such as ditch, ravine, stream, cave should be virtual, the protruding part such as peak, mountain range is practical, with a combination of virtual and practical to be decent. Therefore, the stacking of autumn scenery is also the extrapolation of the relationship between the virtual and the practical. By introducing this concept of protruding as "practical" and concave as "virtual" into the product design, it conforms to the blankness and void of the law of morphological beauty. An example is the recliner designed by the renowned architectural furniture designer Alvar Aalto (Figure 5). The seat and backrest of this chair are designed as a whole, and the armrest and support of the chair are bent by two metals, with the hollow structure contrasting with the former to constitute an echo of the virtual and the practical. Viewed from the side, as if one is sitting in the air, it is easily attracting people's attention, arousing their interest and generating a deep impression, which is both practical and highly decorative and modern.

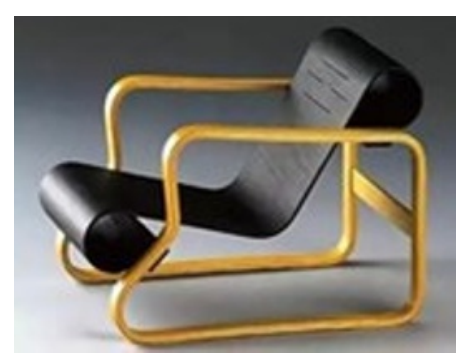

Figure 5. Reclining chair designed by Alva Alto

\subsection{Smart Use of Associations}

Thanks to the unique design approach, we can recognize the seasons corresponding to the "spring, summer, autumn and winter" rockeries in Yangzhou Geyuan Garden, not just seeing the rockeries, but also the meanings underlying the rockeries. For example, to express the theme of spring, the bamboo, which symbolizes vitality and vigor, is associated with the bamboo shoots that burst out of the ground, signifying the mood of spring bamboo shoots after the rain. Such association can also be applied to the design of product models. For example, the design master Naoto Fukasawa's WIIK mobile phone (Figure 6) was inspired by the association of things around him. He associated the touch of a peeled potato's angular surface with the sense of touch, enabling the user to quickly locate it whenever he or she touches this unique angular surface while searching for the phone in their pocket. This associative approach taps into the relationship between user behavior and the subconscious, enriching the product and rendering it more fascinating.

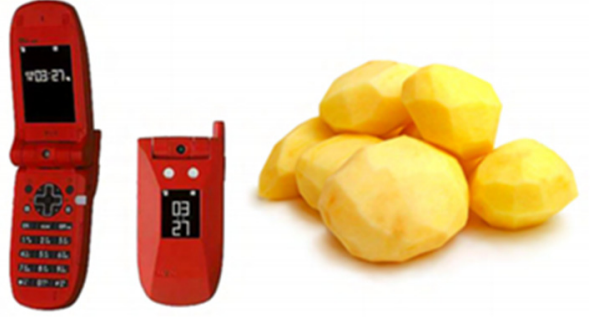

Figure 6. WIIK mobile phone designed by Naoto Kanazawa

The autumn scenery is composed of majestic "yellow stones", which represent the autumn harvest season in people's mind. The color of the "yellow stone" per se brings out the atmosphere of autumn, exploiting people's psychological response to the natural seasons. The concept of color to enhance the atmosphere should be implemented in the design of the product's exterior color, as in "stone selection", taking into account the product's application environment, the user's psychology, and the physiological response. Only in this way can the product penetrate the people's heart and allow the color to perform its proper function. For example, in designing for the Winter Olympics, white or cold blue is usually chosen as the dominant color to emphasize the icy atmosphere of winter.

For winter scenery, the rockery made of snow stones shines brightly in the light, whereas it is faintly white against the light, reminding one of the residual snow. Twenty-four wind holes are carved on the back wall to respond to the meaning of "the north wind whistling cold snow light". There are windows on the west wall of the winter scenery, allowing people to glimpse the view of the spring scenery, being reminiscent of "winter is approaching, is spring still distant?" A hollow partition is adopted between the winter scenery and the spring scenery to integrate the "spring and winter". Replicating such a partitioned treatment, the element of "hollowing out" is extracted and applied to the design of the product models. For example, Vacheron Constantin's 30067/000R-8954 mechanical watch (Figure 7) is designed with a hollow-out technique. While people are fascinated by the external model of the watch, they are also lured by the complex structure of the mechanical movement exposed to their eyes. The contrast between the external decorative beauty and the internal mechanical craft beauty offers an aesthetic sense of harmony and unity instead. By combining the appearance and internal structure of the product, this presentation enhances the potential value of the product and demonstrates the morphological beauty law of contrast and harmony.

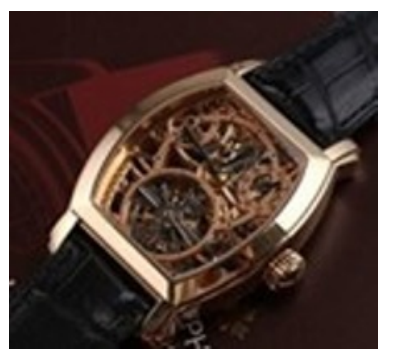

Figure 7. Vacheron Constantin's 30067/000R-8954 mechanical watch 


\section{Conclusion}

The rockery design of the Geyuan Garden expresses the seasonal landscape of "spring, summer, autumn and winter" through different materials and techniques of stone stacking, in combination with the configuration of plants. In an area of less than 3 hectares, by adopting the original technique of "dividing and stacking stones", four rockeries of different morphologies are created respectively, and each is endowed with a unique meaning. The sequence of landscapes conveys the poetic sentiment of "spring scenery is bright and smiling, summer mountains are verdant and drop-like, autumn mountains are fresh and pure, and winter scenery is miserable and drowsy". The summarized and refined characteristics of the four scenery of "spring, summer, autumn and winter" are applied to product design. It can be evidenced through the above cases that the application of the cultural symbols with stone stacking art in Geyuan Garden is practical and feasible, through which the product connotation can be enhanced and the potential value of the product can be raised.

\section{References}

1. Lu Xikang, GUI Jianing, Jia Yanan. Research on stone folding art in Landscape Architecture [J]. Flowers, 2018 (08): 147

2. Dong Ningqian, Liu Danfeng, Wei Xiaojuan. Artistic characteristics and design application of traditional garden stone folding [J]. Enterprise technology and development, 2019 (06): 175-176

3. Ditto

4. Ditto

5. Chen Yingying. Research on morphological language symbols of rockery and stone in Yangzhou garden [D]. Yangzhou University, 2011 